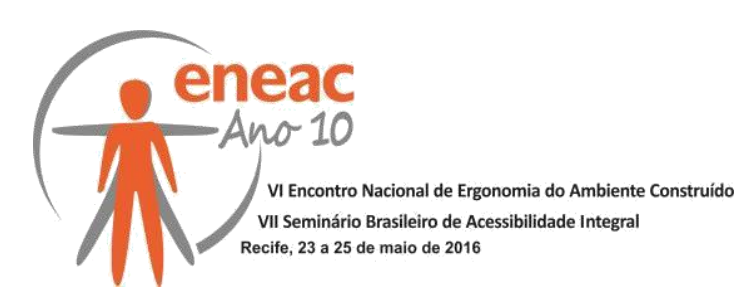

\title{
A NBR 9050 E O USO DO DESENHO UNIVERSAL NA PRODUÇÃO DE ARQUITETURA DE ESPAÇOS EXPOSITIVOS NA CIDADE DE SÃO PAULO NO PERIODO DE 2004 A 2014: ANÁLISE DE PROJETOS DE PAULO MENDES DA ROCHA.
}

\author{
BAPTISTA, Mariana Bertani (1) \\ BERNARDI, Núbia (2) \\ (1) Universidade Estadual de Campinas, Mestranda \\ e-mail: mariberbap@yahoo.com.br \\ (2) Universidade Estadual de Campinas, Doutora \\ e-mail : nubiab@fec.unicamp.br
}

\begin{abstract}
RESUMO
Para prover a equiparação de uso, o Desenho Universal e a Norma Técnica NBR 9050 tornam-se imprescindíveis na produção e adequação dos espaços arquitetônicos. O objetivo desta pesquisa é identificar o impacto da Norma e do DU nos projetos arquitetônicos institucionais executados em São Paulo, entre 2004 e 2014 - intervalo entre as duas últimas revisões da Norma, período no qual a produção do arquiteto Paulo Mendes da Rocha se destacou. Espera-se definir como a Norma e o DU influenciam o programa arquitetônico na concepção do projeto, através de revisão bibliográfica, análise qualitativa dos edifícios e surveys direcionados a diferentes públicos.
\end{abstract}

Palavras-chave: Desenho Universal; NBR 9050; Arquitetura Programática.

\begin{abstract}
To provide the equalization of use, Universal Design and the Brazilian Technical Norm NBR 9050 become indispensable for the production and adaptation of architectural spaces. The objective of this research is to identify the impact of the Norm and UD in institutional building projects executed in São Paulo between 2004 and 2014 - period between the last two revisions of the Norm, in which the production of the architect Paulo Mendes da Rocha stood out. It's expected to define how the Norm and UD influence the architectural program, through literature review, qualitative analysis of targeted buildings and surveys to different audiences.
\end{abstract}

Keywords: Universal Design; Brazilian Technical Norm NBR9050; Programmatic Architecture.

\section{INTRODUÇÃO E JUSTIFICATIVA - SÍNTESE DA BIBLIOGRAFIA FUNDAMENTAL}

No Brasil, as normas técnicas são elaboradas e atualizadas pela Associação Brasileira de Normas Técnicas (ABNT). A primeira Norma Técnica Brasileira específica para acessibilidade, foi redigida em 1985 e intitulada NBR 9050 - Adequação das edificações, equipamentos e mobiliário urbano à pessoa portadora de deficiência. Em três décadas a Norma passou de um documento estritamente focado em pessoas com alguma deficiência, 


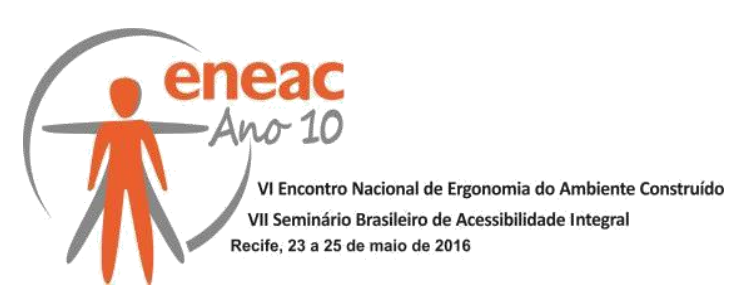

para em sua versão atual (2015), um documento universal, atentando-se para as necessidades de mobilidade e comunicação de diferentes tipos de usuários.

Neste contexto o Desenho Universal (DU) é primordial para a produção dos espaços urbanos e arquitetônicos. O objetivo do Desenho Universal é beneficiar simultaneamente todas as idades e capacidades providenciando um ambiente de integração, que estabeleça formas comuns de vida, de aprendizagem e de trabalho entre pessoas deficientes e não deficientes (STORY, 2001; STEINEMANN, 1994).

O foco deste estudo são os edifícios institucionais na cidade de São Paulo. Em arquitetura, o edifício institucional é o espaço público cujas características principais são a abrangência de usuários, a coletividade e uso social, a recepção a grande e variado número de visitantes e, em geral, o fato de serem espaços construídos em locais de fácil acesso, com uma arquitetura que marca forte presença na paisagem urbana.

Para edifícios institucionais, os programas tendem a ser mais complexos, por isso seu estudo torna-se ainda mais interessante. O Programa Arquitetônico é um dos determinantes do projeto, principalmente nas fases iniciais, que ao lado do partido tomado, do local de implantação e das restrições legais inerentes ao tipo de projeto, norteiam as decisões projetuais, no intuito de produzir uma edificação que atenda às expectativas do público usuário.

Em São Paulo, a ultima década foi marcada por novos projetos arquitetônicos, que necessariamente contemplaram a acessibilidade devido a diversos fatores, como: Plano Diretor Participativo; criação de leis de apoio à inclusão; e ao fato de ter sido cidade-sede da Copa do Mundo. Neste mesmo intervalo de tempo (2004 a 2014) ocorreram as duas consultas públicas para a atualização da Norma NBR 9050, em 2008 e em 2012. Diante deste cenário, realizou-se uma pré-seleção dos projetos, executados ou em execução na cidade de São Paulo, no período entre 2004 e 2014, o que permitiu definir as tipologias disponíveis para este estudo.

Nesta pré-seleção foi possível aferir que a tipologia que melhor cabe ao estudo é a de Galeria Expositiva, devido ao seu caráter de acesso público e função didática. A importância de aprofundamento desta tipologia ocorre pelo fato da mesma ter sofrido alterações programáticas ao longo da história, como apontou ARANTES (1991). Nesta primeira fase de pesquisa se destacou a produção de edifícios institucionais do arquiteto Paulo Mendes da Rocha e as obras selecionadas foram a Galeria Vermelho e a Galeria Leme.

\section{OBJETIVOS GERAIS E OBJETIVOS ESPECÍFICOS}

A proposta principal desta pesquisa consiste em investigar como o Programa de Necessidades é influenciado pela Norma NBR9050 e pelo DU na arquitetura de edifícios institucionais recente da cidade de São Paulo, contemplando o período entre 2004 e 2014.

Os objetivos específicos são: definir um panorama da arquitetura de edifícios institucionais de caráter expositivo produzidos na cidade de São Paulo no período de 2004-2014; verificar os arquitetos citados por sua produção; selecionar os edifícios; diagnosticar o impacto da Norma NBR9050 e do DU nas edificações, o impacto da Norma NBR9050 e do DU no Programa Arquitetônico, os aspectos de DU comuns entre os projetos selecionados; por fim elaborar a Dissertação de Mestrado com base na análise dos resultados obtidos nos diagnósticos. 


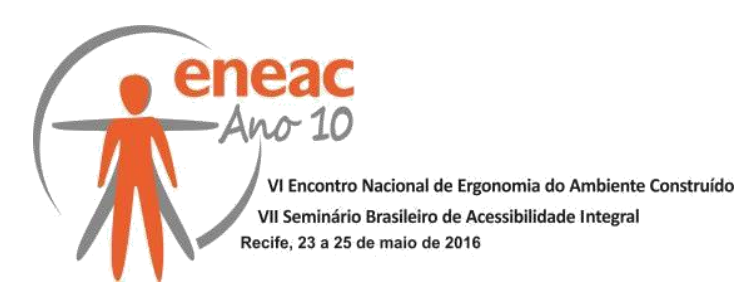

\section{METODOLOGIA}

A abordagem se dará através do levantamento e análise da bibliografia pertinente, referentes à Norma NBR9050, Projetos Institucionais, Programa de Necessidades, à Acessibilidade, ao Desenho Universal e sobre a obra do arquiteto; seguida pela análise qualitativa dos projetos. Nesta pesquisa serão feitas dois tipos de análise qualitativa, uma quanto aos critérios do processo de projeto em relação aos "materiais estáveis" - tijolos, concretos, vidros - e "materiais instáveis" - luz, som, temperatura - com base na interpretação da arquitetura de UNWIN (2003). No segundo momento serão analisados os Programas de Necessidades, os projetos e edifícios através da perspectiva do usuário proposta por VAN DER VOORDT (2013).

As Fases da pesquisa definem-se abaixo:

I - PESQUISA DOS MATERIAIS: Levantamento e análise bibliográfica nos temas: DU, acessibilidade, programa de necessidades, Projetos Institucionais e obra do arquiteto (Paulo Mendes da Rocha);

II - ESTUDO: Levantamento de documentação dos projetos selecionados; Estudo de Campo - visitas técnicas; entrevistas com funcionários, usuários, arquitetos; fotos e desenhos de observação dos ângulos do projeto que melhor representarem o Desenho Universal (nomeados „ângulos universais" pela pesquisadora);

III - DIAGNÓSTICO: Análise preliminar com base no levantamento bibliográfico; Análise dos projetos com base no levantamento documental. Diagnóstico individual e diagnóstico comum entre os projetos; Discussão dos resultados.

\section{RESULTADOS ESPERADOS}

Pretende-se obter dados relevantes sobre a aplicação do Desenho Universal e da Norma NBR 9050 no Programa de Necessidades de projetos representativos da produção arquitetônica institucional de caráter expositivo da cidade de São Paulo no período de 2004 a 2014. Também é objeto desta pesquisa discutir em que medida a arquitetura institucional é receptiva aos usuários com diferentes habilidades e necessidades.

\section{REFERÊNCIAS E BIBLIOGRAFIA RELEVANTE}

ARANTES, O. B. F. Os Novos Museus. Novos estudos CEBRAP, 1991.

MOREIRA, D. C. Os princípios da síntese da forma e a análise de projetos arquitetônicos. Campinas, SP: [s.n.], 2007.

STEINEMANN, C. F.(1994). The Vocational Integration of the Handicapped, In, EASE - Edition n요 - pp.6 - 13. Vários (1994). Necessidades Educativas Especiais

STORY, M. F. Principles of Universal Design in PREISER, W. F. E.; OSTROFF, E (ed). Universal

Design Handbook. New York: Mc-Graw-Hill, 2001.

UNWIN, S. A análise da arquitetura. Tradução técnica: Alexandre Salvaterra. $3^{\underline{a}}$ edição, Porto Alegre: Bookman, 2013.

VOORDT, T.J.M. van der. Arquitetura sob o olhar do usuário. Tradução Maria Beatriz de Medina. São Paulo: Oficina dos Textos, 2013. 